\section{Shielded twisted pair}

O. Colhoun

Institut für Laboratoriumsmedizin, Klinikum Frankfurt

Höchst, Frankfurt am Main, Deutschland

Synonym(e) Twisted-Pair-Kabel

Englischer Begriff STP; shielded twisted pair
Definition Netzwerkkabel zur Verbindung von Computern.

Beschreibung Deutsch „abgeschirmtes verdrilltes Kabelpaar": Das Kabel besteht aus mindestens zwei verdrillten Leitungen und ähnelt dem einer Telefonleitung. Beim STPKabel ist jede Ader einzeln abgeschirmt; dies im Gegensatz zum UTP (Unshielded-twisted-pair-Kabel). 